\title{
PROCESSING OF THE BOTTOMHOLE ZONES OF OIL WELLS WITH USE OF THE CARBON NANOMATERIALS
}

\author{
D. A. Baiseitov ${ }^{1}$, M. I. Tulepov ${ }^{1}$, S. Tursynbek ${ }^{1}$, L. R. Sassykova ${ }^{*}$, \\ M. Nazhipkyzy ${ }^{1}$, Sh. E. Gabdrashova ${ }^{1}$, Y. V. Kazakov ${ }^{1}$, I. O. Pustovalov ${ }^{1}$, \\ F.Y. Abdrakova ${ }^{1}$, Z. A. Mansurov ${ }^{1}$ and A. B. Dalton ${ }^{2}$ \\ ${ }^{1}$ Al-Farabi Kazakh National University, 050040, Almaty, Kazakhstan \\ ${ }^{2}$ Department of Physics, University of Surrey, Guildford, Surrey GU27XH, United Kingdom \\ *E-mail : larissa.rav@mail.ru
}

\begin{abstract}
The objective of the work was study of compositions on the basis of ammonium nitrate of grade B, magnesium, aluminium, an epoxy resin and the nanostructured soot as the gas-generating composition of gas generator for processing of oil wells. In the work the regularities and features of combustion of carbonaceous nanomaterials in two gas generating compositions with regard to the conditions of the oil wells were determined. Influence of various amount of the nanostructured soot on regularities of combustion of pyrotechnic gas generator composition was researched. The content of the combustion products by the "Terra" program for composition No.2 was determined. An optimal composition for the processing bottomhole zones of oil wells was offered.

Keywords: oil well, combustion rate, bottomhole zone of oil wells, nanostructured soot
\end{abstract}

@ RASĀYAN. All rights reserved

\section{INTRODUCTION}

Today the combustion processes are widely used for the processing oil wells. ${ }^{1-3}$ One of the cheapest and available methods of impact on bottomhole zone treatment (BHZ) is the method of thermogas-chemical method of influence with use of power saturated systems of various nature. There is a large number of thermogas-chemical sources on the basis of gunpowder, mixed fuels and pyrotechnic systems. ${ }^{4-7}$ One of the efficient ways of increase oil recovery of the well is acid treatment of a bottomhole formation zone. ${ }^{8,9}$ For example hydrochloric acid is used for processing of the layers composed of carbonaceous rocks and so-called mud acid (acid clay) is used as the chemical reagent for processing of layers from terrigenous rocks. ${ }^{10-12}$

In this work the compositions on the basis of ammonium nitrate of grade $\mathrm{B}$, a magnesium, aluminium, an epoxy resin and the nanostructured soot as the gas-generating composition of gas generator for processing of oil wells were studied.

\section{EXPERIMENITAL}

In this study as the object of research two pyrotechnic gas generating compositions were taken. They were prepared with different ratios of the components: ammonium nitrate in powder (AN), nanostructured soot (NS), magnesium powder, aluminium powder, epoxy resin. Epoxy resin is applied as a binder and combustible additive. For the compounds synthesis a granulated AN was milled. The ingredients were mixed in a porcelain mortar. The composition was formed and subjected to drying at a temperature of 323-333 K during $1 \mathrm{~h}$. Composition No.1, wt., \%: AN:35-40; NS:0-5; magnesium powder: 15.0-20.0; epoxy resin: 35.0-40.0. Composition No.2, wt., \%: AN: 37.0-42.0; NS: 0-5.0; magnesium powder: 2.57.5; epoxy resin: 37.0-42.0; aluminum: 2.5-7.5. Finally the compositions were laid into a cardboard cartridge with a diameter of $1.0 \mathrm{~cm}$ and $10.0 \mathrm{~cm}$ high (Figure-1). Combustion process was initiated from the top part of the cartridge with the initiation composition $(50.0 \% \mathrm{Mg}+50.0 \%$ smokeless powder). A linear speed of the compositions combustion was determined by dividing the height of the cardboard for the duration of combustion of compositions. The flashpoint of compositions was determined by 
combustion in the reactor (Figure-2). For fixation the temperature of compositions combustion an optical pyrometer Raytek $3 \mathrm{i} 1 \mathrm{M}$ was used. Each study was performed five times, then the average value was defined.

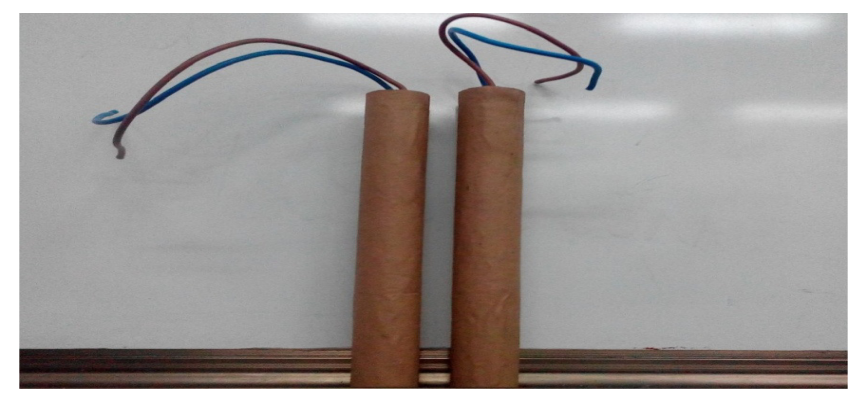

Fig.-1: A gas generator cartridge applied in the industry

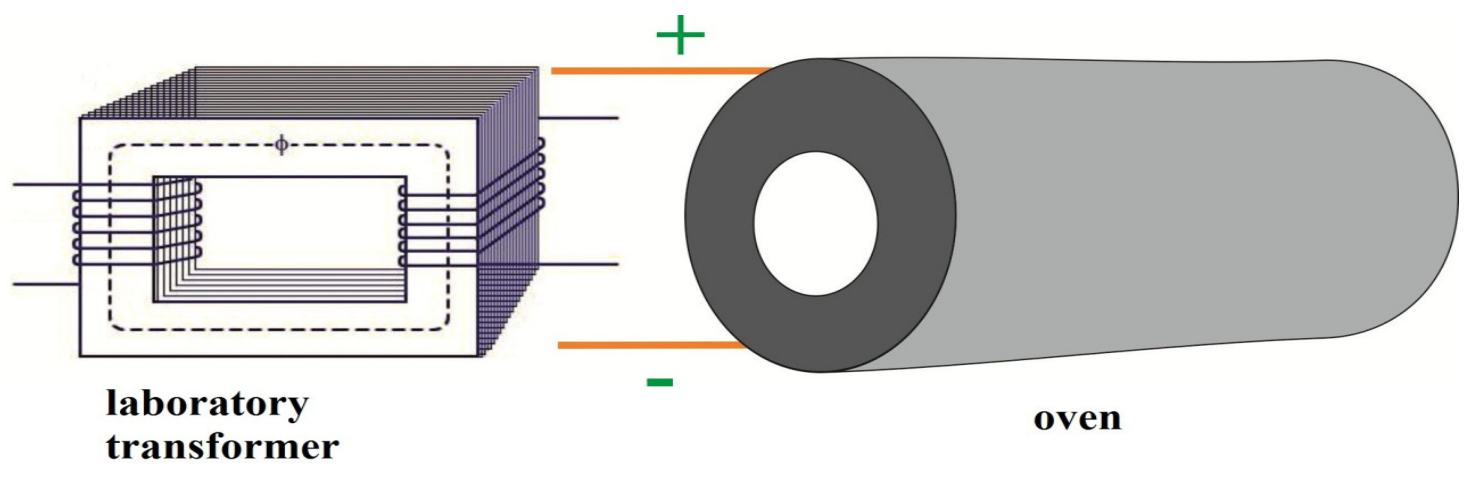

Fig.-2: The reactor used in the work for flash point testing of pyrotechnic compositions

\section{RESULTS AND DISCUSSION}

Research of composition No.1 (Figure-3, Table-1) showed that combustion rate of the investigated pyrotechnic composition was within values $2.5-7.28 \mathrm{~mm} / \mathrm{s}$. and flash point - at $348 \mathrm{~K}$. It was revealed that combustion temperature of this composition was equal to $2273 \mathrm{~K}$. The data of Table-1 and Figure-3 note that the amount of NS is not particularly affect the combustion temperature of the samples. As it is seen from the Table, influence of NS on burning rate of pyrotechnic composition depends on the content of NS in composition. As a part of composition No.1 $0.1 \%$ of NS reduces burning rate of composition by $20 \%$, but with increase in amount of NS rate of combustion increases and the increase of speed reaches about $30-40 \%$.

Table-1:The studied samples with NS

\begin{tabular}{c|c|c|c|c|c}
\hline \multicolumn{3}{|c|}{ Composition No.1 } & \multicolumn{3}{c}{ Composition No.2 } \\
\hline $\begin{array}{c}\text { NS } \\
\text { wt. }\end{array}$ & $\begin{array}{c}\text { The } \\
\text { temperature of } \\
\text { combustion, K }\end{array}$ & $\begin{array}{c}\text { The } \\
\text { combustion } \\
\text { rate, U, } \\
\mathrm{mm} / \mathrm{s}\end{array}$ & $\begin{array}{c}\text { NS content, } \\
\% \text { wt. }\end{array}$ & $\begin{array}{c}\text { The } \\
\text { temperature of } \\
\text { combustion, K }\end{array}$ & $\begin{array}{c}\text { The } \\
\text { combustion } \\
\text { rate, U, } \\
\mathrm{mm} / \mathrm{s}\end{array}$ \\
\hline 0.0 & 1184 & 2.5 & 0.0 & 1229 & 0.11 \\
\hline 0.1 & 1196 & 2.0 & 0.1 & 1248 & 0.07 \\
\hline 0.3 & 1198 & 2.7 & 0.3 & 1246 & 0.085 \\
\hline 1.0 & 1210 & 3.8 & 1.0 & 1258 & 0.05 \\
\hline 1.5 & 1184 & 5.2 & 1.5 & 1239 & 0.13 \\
\hline 5.0 & 1226 & 7.28 & 5.0 & 1245 & 0.25 \\
\hline
\end{tabular}


In conditions of oil wells any composition of gas generator should burn for a long time, so in this work in order to decrease the combustion rate into the composition a powder of aluminum was added. The formulations with aluminum under the condition of identical metal milling burn much slower than formulations with magnesium. ${ }^{13-15}$ Besides, AN is applied if a large time of combustion of mixture is necessary because it has low speed of combustion ${ }^{16-19}$ in a case with the composition No.1 (Table) without aluminium addition the combustion rate was higher in comparison with the rate of the composition No.2. Investigations of composition No.2 (Table-1, Figure-4) show that combustion rate of the studied pyrotechnic formulation was varied from 0.11 to $0.25 \mathrm{~mm} / \mathrm{s}$., and flash point was at $383 \mathrm{~K}$. The combustion temperature of this composition was equal to $2773 \mathrm{~K}$. In the case of increasing the content of NS (Figure-4) wasn't observed a rectilinear dependence of increasing the combustion rate of the pyrotechnic composition, as shown in Figure-3. Figure-4 shows that NS content in the composition may both increase the rate of combustion (on 52.0-60.0\% with $0.3 \%$ and $5.0 \%$ of NS) and to reduce it (on about $37.0-60.0 \%$ at 0.1 and $1 \%$ of soot). At $1 \%$ of NS there was the lowest burning rate equal to 0.05 $\mathrm{mm} / \mathrm{s}$. The data of Figure-3 and Figure-4 show that the optimum composition for the processing of oil wells is the composition No.2, wt. \%: AN - 42.0; NS - 1.0; magnesium powder - 7.5; epoxy resin - 42.0, aluminium - 7.5.

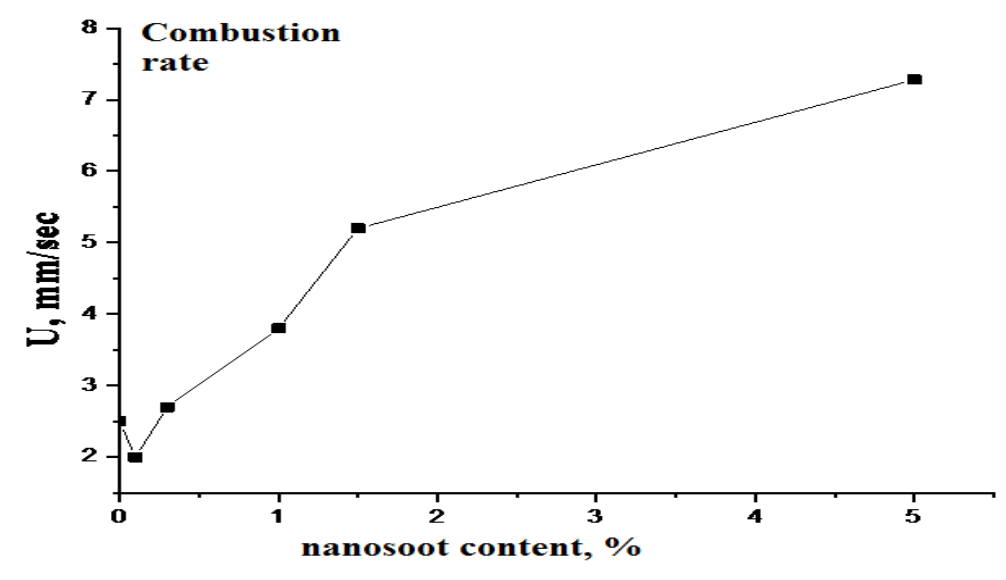

Fig.-3: Combustion of the composition No.1

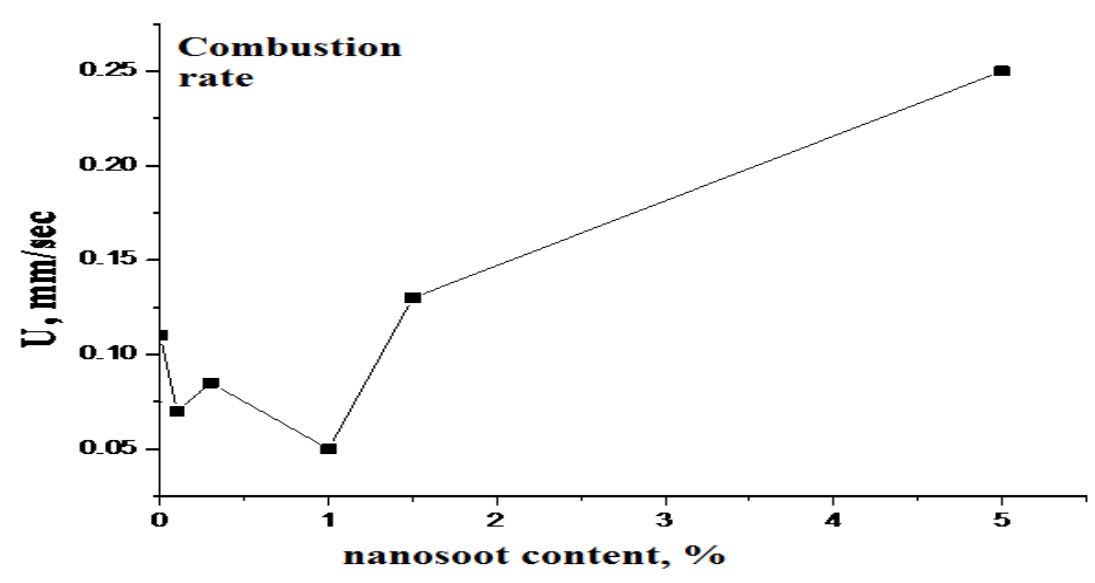

Fig.-4:Combustion of the composition No. 2

By "Terra" program calculation for the composition No.2 was determined the composition of the combustion products in the temperature range of 300-2000 K and an atmospheric pressure of $0.100 \mathrm{~Pa}$. Figure-5 shows the composition of the gas phase of the process gasification. It is revealed that the gas 
phase consisted mainly of synthesis gas $\left(\mathrm{CO}+\mathrm{H}_{2}\right)$, a thermodynamically stable to by-products of the gasification process. At $\mathrm{T}=1400 \mathrm{~K}$, the concentration of the synthesis gas in the gas phase reaches the maximum - 52.5\%. It was shown that the concentrations of $\mathrm{CH}_{4}$ and $\mathrm{CO}_{2}$ impurities reduced to zero at increasing the temperature up to $1200 \mathrm{~K}$. Nitrogen-containing substances are mainly presented by the molecular nitrogen and its concentration is decreased at temperature increase due to emergence of synthesis gas and increase of its concentration in a gas phase. At temperature $1950 \mathrm{~K}$ concentration of CO reaches the maximal value $(35.0 \%)$. Concentration of molecular hydrogen $\left(\mathrm{H}_{2}\right)$ reaches the maximum $(55.0 \%)$ at $\mathrm{T}=1600 \mathrm{~K}$ and in the range of temperatures $400-1300 \mathrm{~K}$ is sharply increased. For determination of the morphology and sizes of the resulting soot particles EM-studies of soot samples were carried out (Figure-6).

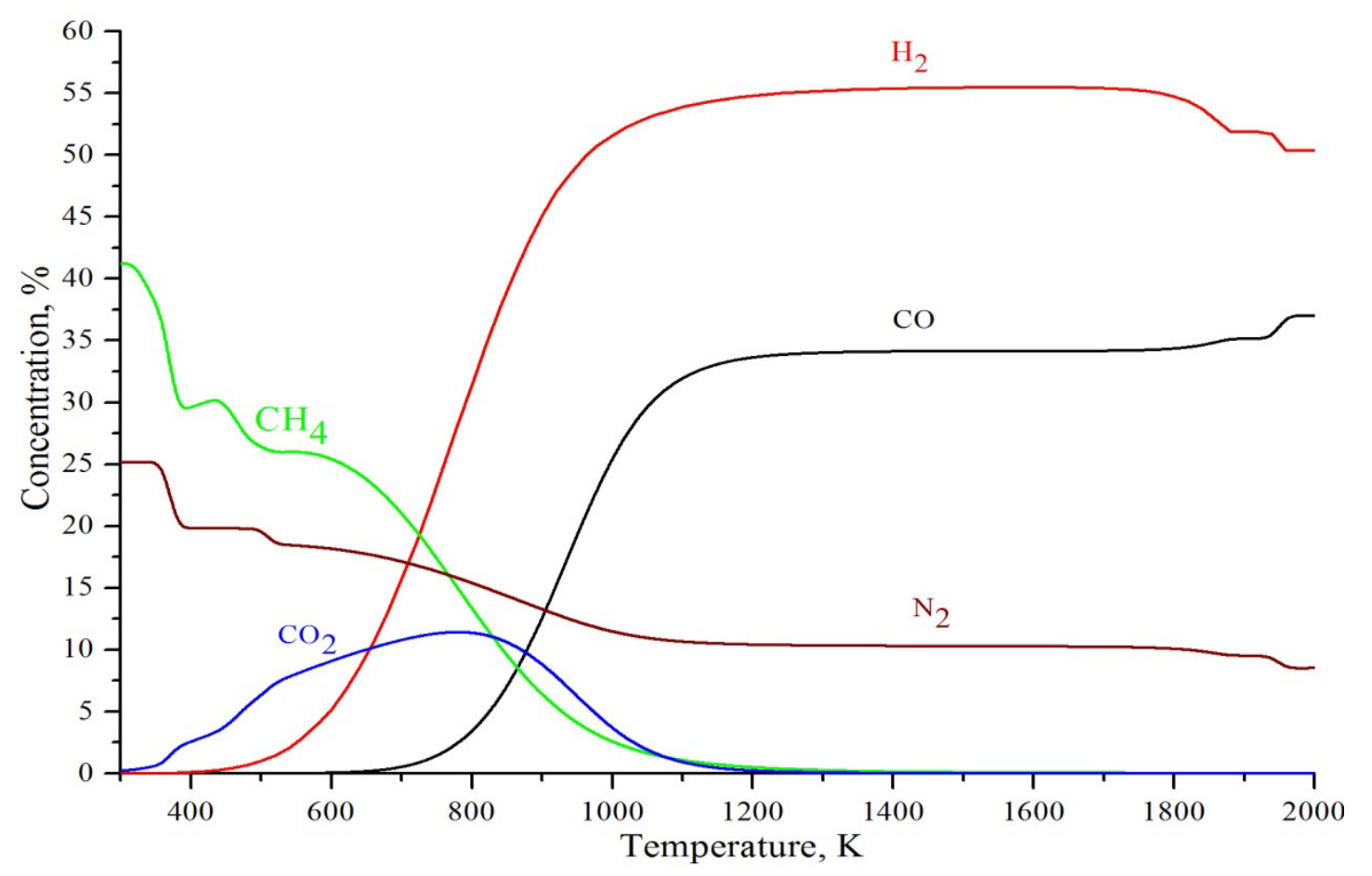

Fig.-5: Temperature dependence of the concentration of components in the gas phase in the composition No.2

The size of soot particles is within 20.0 - $45.0 \mathrm{~nm}$ (Figure-6a). The sample consists of rounded dominant (in the investigated grid about 70\%) and the film (about 30.0\%) formations. The size of the flattened, rounded particles, often collected in volumetric units was approximately $15.0-50.0 \mathrm{~nm}$ (Figure-6a).

The elemental composition of soot sample shows that the sample is composed of $92.0 \%$ carbon and $8.0 \%$ oxygen (Figure-6b). Thus the results of compositions test and EM-studies showed that the composition with $1.0 \%$ the content of NS with sizes less than $50 \mathrm{~nm}$ exactly reduced the rate of combustion, which in turn promoted slow burning of gas generator composition.

\section{CONCLUSION}

The effect of different amounts of soot on the regularities of burning a pyrotechnic gas generator composition was studied. It was revealed that soot depending on the amount in the composition may increase the rate of combustion (on approx. 52.0-60.0\% with $0.3 \%$ and 5.0 of soot) and decrease it (on approx. 37.0-60.0\% at 0.1 and $1.0 \%$ of soot). By adding of $1.0 \%$ of nanostructured soot the lowest rate of combustion- $0.05 \mathrm{~mm} / \mathrm{s}$. was reached. By calculation accordingly to "Terra" program the content of the combustion products for the composition No.2 was defined. The optimal composition for the processing of oil wells was the composition No.2 with the content of nanostructured soot $1.0 \%$. 


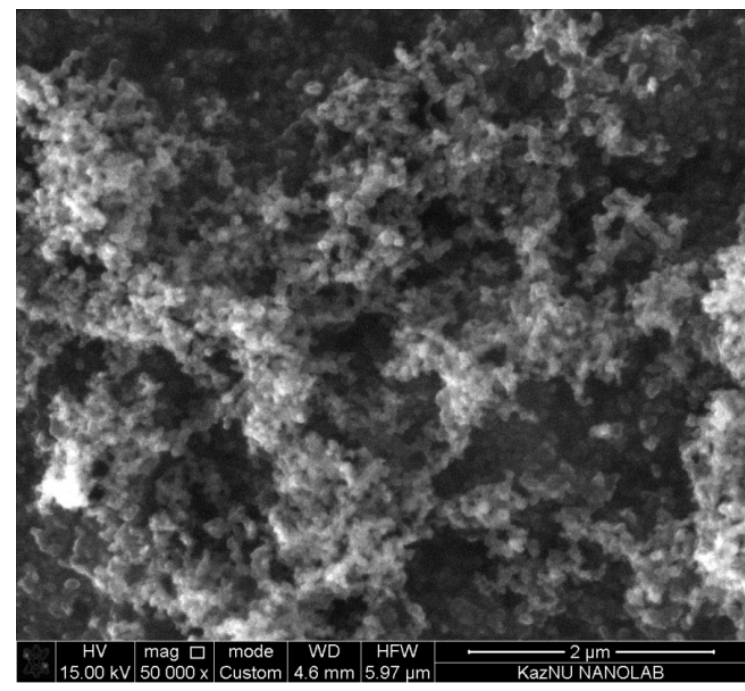

(a)

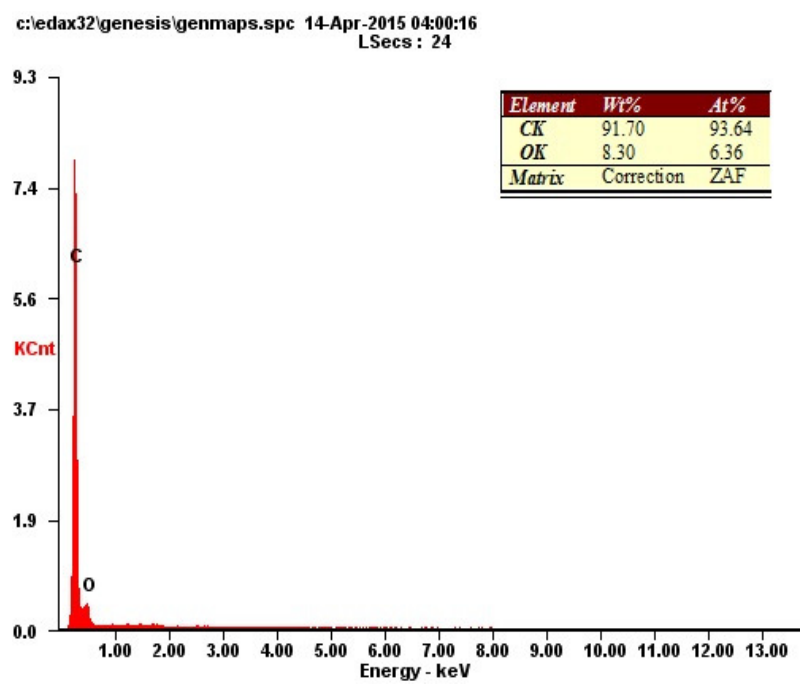

(b)

Fig.- 6: (a) SEM - image of the sample of soot; (b) The elemental analysis of the sample of soot

\section{REFERENCES}

1. D. Swanepoel, O. Del Fabbro, W. W.Focke, Propellants, Explosives, Pyrotechnics, 35(2), 105(2010).

2. S. S. Klyukin, R. I. Rezyapov, Oil and Gas Business, 6, 378(2014).

3. L. F. Ayala H., Z. T. Karpyn, Petroleum Science and Technology, 25(8), 1099(2007).

4. Z. A. Mansurov, M. I. Tulepov, Y. V. Kazakov, A. N. Djubanshkalieva, D. A. Baiseitov, S. Tursynbek, F. Y. Abdrakova, G. A. Esen, K. K. Munasbayeva, News of National Academy of RK, Series of Chemistry and Technology, 414(6), 61(2015).

5. M. A. Ahmadi, M. Galedarzadeh, S. R. Shadizadeh, Petroleum, 2(3), 258(2016).

6. E. A. Ivliev, Surf. Eng. and Appl. Electrochem. 45(1), 21(2009).

7. S. K. Shahenoor Basha, G.Sunita Sundari, K.Vijay Kumar, M.C.Rao, Rasayan J.Chem., 9(3), 348 (2016).

8. G. R.Izmaylova, A. V. Gulimov, Oil and Gas Business, 6, 159(2013).

9. M. A. Sherief, A. A. Hanna, A. A. Elkheshen, A .A. Abd El Aty, Rasayan J.Chem., 9(3), 531(2016).

10. D. A.Baiseitov, Sh.E.Gabdrashova, A.K.Akylbai, O.Dalelkhanuly, Zh.B.Kudyarova, L.R. Sassykova, M.I. Tulepov, Z.A. Mansurov, Int. J. Chem. Sci., 14(1), 261(2016).

11. D. Decroocq, Oil \& Gas Science and Technology, 58(3), 331(2003).

12. X. Kang, F. Yang, J. Luo, Y. Tang, Combustion Science and Technology, 187(6), 963(2015).

13. K. U. Shah, J. E. Rivera, Policy Science, 40(4), 265(2007).

14. J. W. Chen, Ch. Ch. Li, H. W. Lin, J. T. Yang, Combustion Science and Technology, 187(9), 1317(2015).

15. L. Sassykova, Sh. Gil'mundinov, A. Nalibayeva, I. Bogdanova. Revue Roumaine de Chimie, 62(2), 107(2017).

16. F. P. Agterberg, Intern. J. of Oil, Gas and Coal Techn, 6(1), 63(2013).

17. S. Sendilvelan, K. Bhaskar, Rasayan J.Chem., 9(4), 692(2016).

18. M. J. Sullivan, D. L. Belanger, W. F. Stewart, SPE Reservoir Evaluation \& Engineering, 5(1), 60 (2002).

19. Z. A. Mansurov, M. I. Tulepov, Y. V. Kazakov, A. N. Djubanshkalieva, D. A. Baiseitov, A. N. Temirgalieva, Alan B. Dalton, News of National Academy of RK, Series of Chemistry and Technology, 414(6), 41(2015).

[RJC-1644/2017] 